\title{
Correction to: On the Automatic Nature of Threat: Physiological and Evaluative Reactions to Survival-Threats Outside Conscious Perception
}

\author{
David S. March ${ }^{1} \cdot$ Lowell Gaertner $^{2} \cdot$ Michael A. Olson $^{2}$
}

Published online: 21 February 2022

(C) The Society for Affective Science 2022

\section{Correction to: Affective Science}

https://doi.org/10.1007/s42761-021-00090-6

The authors of the Affective Science article "On the Automatic Nature of Threat: Physiological and Evaluative Reactions to Survival-Threats Outside Conscious Perception" have noted an error in their online published article. Here is the issue:

In the Method section of Study 2, a sentence currently reads: "Participants sampled the noise (i.e., the startle probe-a 50ms binaural burst of $1000 \mathrm{~Hz}, 100 \mathrm{~dB}$ white noise; calibrated daily) and completed 144 trials that each (1) began with a 2000 ms centrally located pre-mask of a mosaic that was (2) replaced by a 2 -ms image, that was (3) backward masked by a 3000-5000-ms mosaic (rotated $90^{\circ}$ clockwise) and, (4) ended with either a 4000-ms blank screen, or, for trials including a startle-probe, a text-box prompting the perceived loudness $(85-115 \mathrm{~dB})$ of the noise."

The relevant part of the sentence should read:

“(2) replaced by a $21-\mathrm{ms}$ image”.

This erratum is presented to fix these errors.

The original article has been corrected.

The online version of the original article can be found at https://doi.org/ 10.1007/s42761-021-00090-6

David S. March

march@psy.fsu.edu

1 Florida State University, Tallahassee, FL, USA

2 University of Tennessee, Knoxville, TN, USA 